\title{
Aligning Strategic Orientation with Information Resources
}

\author{
Eric W. Ford ${ }^{1}$, Timothy R. Huerta ${ }^{2}$, Nir Menachemi ${ }^{3} \&$ Dmytro Babik ${ }^{4}$ \\ ${ }^{1}$ Department of Adult Health, School of Nursing, University of North Carolina Greensboro, USA \\ ${ }^{2}$ Departments of Family Medicine and Biomedical Informatics, College of Medicine, The Ohio State University, \\ USA \\ ${ }^{3}$ School of Public Health, University of Alabama Birmingham, USA \\ ${ }^{4}$ University of North Carolina Greensboro, USA \\ Correspondence: Eric W. Ford, Professor, Department of Adult Health, School of Nursing, University of North \\ Carolina Greensboro, USA. E-mail: ewford@gmail.com
}

Received: October 24, 2013

doi:10.5430/jms.v4n4p32
Accepted:November 1, 2013

Online Published: November 9, 2013

URL: http://dx.doi.org/10.5430/jms.v4n4p32

\begin{abstract}
In today's digital society, technology-based resources are emerging and changing far more rapidly than organizational systems and structures. While information management is critical to strategy at both the formulation and implementation stages, strategic decisions often must be made quickly, and with less rationality than is desirable. This paper provides an analytical framework based on the types of information needed for specific strategic orientations. The proposed framework, or information resource matrix (IRM), integrates the strategy typology of Miles and Snow (1978), the uncertainty dimensions of Milliken (1987), and the decision-making model of Simon (1963). The IRM identifies a firm's information needs for a given strategic orientation. Using the IRM, managers can tailor information systems to fit their strategic information needs.
\end{abstract}

Keywords: alignment of IS plans with business plans, corporate strategy, task uncertainty, task structure, competitive IS

\section{Introduction}

In today's digital society, technology-based resources are emerging and changing far more rapidly than organizational systems and structures (Gilchrist, Mooers, Skrubbeltrang, \& Vachon, 2012). As a result, the rate at which technological change occurs is outpacing managers' abilities to anticipate, plan for, and implement information system change. In addition, most industries are experiencing rapid and unpredictable environmental change. Evaluating the general environment and its effect on an organization has long been recognized as more difficult under conditions of uncertainty than during predictable periods. Strategic decisions often must be made more quickly, and with less rationality than is desirable. Further, many top-level managers are struggling to understand their role in aligning information technology (IT) with their organization's broader strategies (Earl \& Feeney, 2000). The quality of decisions made under these circumstances is almost always less than optimal and frequently less than satisfactory. The need for a linkage between an organization's business domain and its IT objectives is well recognized, but rarely achieved (Reich \& Benbasat, 1996).

The purpose of this paper is to develop a framework that facilitates the IT needs assessments process for managers. In particular, the business strategies, environmental conditions, and decision-making paradigms of organizations are integrated to create an information resource matrix (IRM). The matrix is designed to assist managers in matching their information needs to their organization's strategic postures and prevailing environmental conditions in a more rational manner. Effective use of the matrix may help managers position themselves to more readily accept emerging innovations (Demirci, 2013).

\section{Background}

O’Neill, Pouder, and Buchholtz (1998; Reich \& Benbasat, 2000) cite environmental turbulence as a major factor in strategy diffusion, noting that during periods of greater uncertainty, "organizations may seek change and are more 
likely to imitate other organizations, especially if those organizations are norm setters" (p. 102). Further, the greater the amounts of contact between competing firms, the more likely firms are to adopt their competitors' strategies (Korn, 2004; Parnell, 2013). Notwithstanding the quality of outcomes - or lack thereof - achieved with this approach, companies that mimic another's strategy are reacting, which has been defined as an absence of deliberate strategy formulation (Miles et al., 1978). In essence, formulating an effective strategy in the face of extraordinary environmental uncertainty is a daunting task, but one regularly encountered by managers. Strategic management, even under constrained rationality, is preferable to reactionary behavior. Because no single strategy is universally superior, when strategic management is used, a contingency approach that considers organizational characteristics (Sambamurthy \& Zmud, 1999) and objectives (Reich \& Benbasat, 2000) typically is employed in order to select a strategy that reduces perceived risk from environmental factors.

The sine qua non for reducing risks associated with decision-making under uncertainty is gathering accurate and relevant information at the appropriate times. The information foundation is paramount to developing and implementing an effective organizational strategy. The adequacy of information available to planners in the strategy formulation process inherently restricts the scope of options considered. Insufficient information creates additional uncertainty for the manager, which should stimulate increased environmental scanning to gather more relevant data. However, without adequate time or resources to judge the utility of information sources, the volume of information available to planners quickly can become overwhelming. The routine difficulty associated with gathering, organizing, and interpreting data in an orderly and efficient fashion increases geometrically when time constraints are imposed. Not surprisingly, many decisions regarding strategic choices are made in a satisficing fashion (Simon, 1960). Firms that are better at turning knowledge into action may drive out much of the risk associated with uncertainty (Pfeffer \& Sutton, 1999).

Information management is crucial to a company's strategy at both the formulation and implementation stages. Scholars have developed tools such as value chains (McKone-Sweet, Hamilton, \& Willis, 2005; Navarro, 2004) and threat, opportunity, weakness, and strength (TOWS) matrices (Weihrich, 1982) to facilitate information analysis in the strategy formulation process. However, these tools do not explicitly incorporate management information system (MIS) requirements for successful implementation. The proposed framework, or information resource matrix (IRM), integrates the strategy typology of Miles and Snow (1978), the uncertainty dimensions of Milliken (1987), and the decision-making model of Simon (1963). The IRM identifies a firm's information needs for a given strategic orientation. Using the IRM, managers can tailor information systems to fit their strategic information needs, and make strategic decisions with greater confidence. Aligning IT to the business strategy and vice versa is critical to harnessing the power of new information systems (Luftman \& Brier, 1999).

\section{Model Dimensions}

Two criteria were used in selecting the dimensions of the IRM. Because the primary purpose of this research is to facilitate the selection of MIS, all of the models were selected for their intuitive simplicity. The second criterion for including a model in the IRM was that the elements could be arrayed in a linear fashion. Porter's (1980) generic strategies, for example, overlap and therefore do not lend themselves to this purpose.

The three dimensions of the IRM must be understood in order to make optimal use of the model as an analytical tool. First, the elements of Miles and Snow's (1978) strategy typology are defined. Next, a brief summary of Milliken's (1987) discussion of environmental uncertainty states is related to the strategic decision process. Third, types of problem structure are delineated using Simon's (1963) decision-making framework. The interactions among these three elements determine the information resources required to formulate and to implement effective strategies.

\subsection{Miles and Snow's Typology}

Miles and Snow's (1978) typology was selected for five reasons, aside from those mentioned previously. First, it describes firms as dynamic systems with dynamic capabilities (Cho, 2013) in interaction with their environment (Hopper, 1990). The typology is a good predictor of firm performance (Ketchen, Thomas, \& Snow, 1993). Further, empirical research has found the typology to be a stable description of firms' characteristics over time (Zahara \& Covin, 1993). Fourth, the typology has been used to explain the fit between IT and a firm's strategy (Zahara \& Covin, 1993). Finally, it provides a commonly employed language for describing strategies that most academically prepared managers will be familiar with. 
The typology specifies three strategic orientations - Defenders, Prospectors, and Analyzers. A fourth category, labeled Reactors, was used to describe organizations when no coherent strategy was evident. Defenders are characterized as seeking to seal off market share and create a stable environment. Their goal is to maintain the status quo, growing incrementally as resources become available. Defenders need information that permits comparison of their organization's performance with the performance of competing firm. The main limitation of this strategy is an inability or unwillingness to respond to changes in the market.

Prospectors can be thought of as being the opposite of Defenders. The Prospector is characterized as always searching for an innovative or a new product lines and discarding old ones. A Prospector needs extensive information resources, which generally are focused externally on market analysis and internally on research and development (Idris \& AL-Rubaie). Whereas Defenders might be characterized as risk adverse, Prospectors balance large risks against a larger set of potential rewards. For many companies, strategic options with less risk than tolerated by Prospectors, but higher returns than expected by Defenders would be ideal.

Similar to Prospectors, Analyzers continuously search for new opportunities. However, they also have the abilities of Defenders for maintaining a core of enduring products and customers. Therefore, Defender and Prospector strategies become tactics that are used by Analyzers to realize their selected strategies. The Analyzer needs robust enterprise information systems that enable optimizing the value of each business unit through all stages of the business lifecycle.

In contrast to these types of deliberately formulated strategies, other companies change direction frequently and seemingly without well-rationed plans. Reactors are characterized as having, "...a pattern of adjustment to [the] environment that is both inconsistent and unstable" (1978, p. 557, emphasis present in original text). When the rate or amount of environmental change surpasses an organization's ability to process information, managers may imitate other firms or rely on intuition rather than objective assessments when making strategic decisions. The simplest form of environmental assessment is to look towards one's competitors for insight. However, even in a best-case scenario, a company would only be recreating someone else's competitive advantage (Christensen, 2001). If multiple competitors are monitored, this reactive stance may lead to seemingly random changes in strategic direction and no advantage at all.

Three important assumptions are made regarding the strategic typology dimension of the matrix. First, reacting is the absence of strategy and therefore is not considered. Second, the strategy orientations are presented from left to right, in the order of increasing difficulty of execution. Generally, more complex strategies require significant integration of organizational resources, and more robust information resources (Lawrence \& Lorsch, 1967). Therefore, information resources identified within the matrix cells become more sophisticated reading from left (resources needed by Defenders) to right (resources needed by Analyzers). The third assumption is that over corporate life spans, the 'best' companies will become Analyzers.

The assertion that companies surviving for extended periods become Analyzers should not be dismissed readily. Consider the Defender strategy. Every product line eventually faces obsolescence, and Defenders will be forced to prospect for a new line to defend. The Prospector, on the other hand, at some time likely will launch one or more failures that lead them to defend an existing product until they have the resources to prospect again. When either Defenders or Prospectors reach a point of punctuated equilibrium they are engaging in an Analyzer strategy. In essence, the Analyzer diversifies risk across strategies, thus reducing the effects of environmental uncertainty.

\subsection{Milliken's Levels of Uncertainty}

Milliken (1987) characterizes strategic problems from an individual manager's perspective using three concepts state, effect, and response uncertainty (Koseoglu, Topaloglu, Parnell, \& Lester, 2013). The three uncertainty dimensions are interdependent. They provide a natural order for considering strategic decisions. In addition, a continuum of decision analyses ranging from completely structured to total non-structured is associated with each type of uncertainty.

The environment external to an organization is composed of suppliers, competitors, consumers, the government, and shareholders - to name only a few examples. State uncertainty (i.e., perceived environmental uncertainty) exists when a manager believes any of the sectors in the external environment is unpredictable (Gonzalez, Llopis, \& Gasco, 2013). However, changing demographic trends, sociological shifts, and technological innovations can disrupt 
linearity, as well. State uncertainty, therefore, may be a managerial perception, an environmental reality, neither, or both.

The unknown potential impact of any change in the general environment may have on an organization is called effect uncertainty. Changes in the general environment may alter the way a company competes or does business in general. For example, legislation may be enacted that prohibits some production technique currently in use. Demographic changes might lead to labor shortages for some job markets. The effects of global change are specific to the organization, in that organizations may experience different effects from the same environmental stimulus.

Intuitively, with greater of amounts of effect uncertainty, the response options available to an organization become less clear. Response uncertainty is "... an inability to predict the likely consequences of a response choice" (Miles et al., 1978, p. 137). Managers who are uncertain about the impacts of response options may delay making decisions. Delay tactics may avoid some financial losses, but lost opportunities also may occur. It is important to recognize that change is not inherently negative. Individuals and organizations often 'pass' on opportunities because they fail to recognize change has already occurred, and they continue to operate under previous (and now outdated) assumptions (Clemons, 1995).

The three uncertainty dimensions are interdependent, and they provide a natural order for considering strategic decisions. First, some understanding of the type or extent of change occurring at the state level is a necessary precursor to assessing the ramifications of reacting to effect uncertainty. Likewise, an estimation of the probable effects is required to develop appropriate responses. Therefore, some quantification of the degree of uncertainty at each level is essential. The IRM framework quantifies uncertainty by categorizing the types of problems or decision structures encountered.

The three types of uncertainty are linearly related, progressing from state uncertainty, through effect uncertainty, to response uncertainty. This assumption of linearity is consistent with Daft and Weick's (1984) conceptualization of relationships among organizational scanning, data interpretation, and learning, which is comparable to Milliken's (1987) framework in many respects. Both models define a general environment, both recognize that this environment is interpreted (or 'enacted', to use Weick's wording), and both acknowledge that large differences exist between the objective and perceived environments. Further, both models have action constructs.

One key action employed by managers in the strategic planning process is environmental scanning. Scanning techniques are used for two primary purposes. A firm may scan or search to identify opportunities to develop new products or markets, or scan to identify threats to the firm's profitability or viability. As environmental uncertainty increases, it is likely that an organization's scanning activities also will increase in volume (Khandawalla, 1972), and the scanning focus may change as well.

\subsection{Simon's Decision-Making Framework}

In an early version of Simon's (1963) framework, he proposed a two-by-two model with the horizontal dimension consisting of descriptive and normative cells. As the IRM analytical framework is prescriptive, only the normative vertical axis, the extremes of which Simon labeled optimizing and satisficing, is used. The terms structured, semi-structured (rather than Simon's 'less-structured'), and non-structured problems are used to quantify the degree to which goals and alternatives are defined.

This nomenclature was selected for two reasons. First, consistent naming provides a clear description of the continuum. Second, using structure rather than program (Simon's alternative term) avoids confusion between the axis dimensions and cell contents, which may contain the term program (e.g. linear programming).

The simplest types of decisions involve problems that have clear goals and known alternatives. Further, the relationship between specific goals and alternatives is known and quantifiable. Problems of this nature are referred to as structured, or programmable, since computer programs and simple algorithms are used routinely as decision aids. By systematizing analysis of the goal-alternative relationships that determine the appropriate decision, structured problems generally can be delegated to line employees. In terms of IT governance, these tasks would be probably be performed by line management (Sambamurthy \& Zmud, 1999). Information generated through these types of decisions may be reported to upper management levels for use in making higher-order decisions dependent upon the technology governance arrangement. 
Semi-structured problems are probably the most common type that managers encounter. Either the goals are clear or there are a finite number of options to consider, but both conditions are not present. The presence of both factors would create a non-structured problem. In most cases, the uncertainty lies with the options available. Under these conditions, managers must select a subset of the identifiable options and use some organizing framework and selection criteria to reach a decision. However, there are several other circumstances that moderate the quality of decisions under this condition.

Three factors potentially may degrade the quality of decision analysis. First is the dilemma of choosing when potentially negative outcomes are among the options. There is evidence that managers will seek to minimize loss rather than optimize returns even under conditions where no risk exists (Highhouse \& Johnson, 1996). Further, under these conditions, managers may delay decision-making hoping a better option will emerge, thus leading to the second element of decision degradation - time constraints. Research observing actual decision-making has shown inconsistency between present and future choices (Simon et al., 1987). Part of the decision-making difficulty can be attributed to the anxiety of working under time pressures. Additionally, individuals making time value decisions have difficulty establishing accurate discount rates. In one sense, this arithmetic issue is an extension of the third problem in decision-making - calculating probabilities intuitively. In clinical studies, individuals did not make effective use of available information, which suggests substantial overconfidence in judgment (Brenner, Koehler, Liberman, \& Tversky, 1996). These problems are compounded when the goals and the alternatives are unknown.

Non-structured problems are characterized as having complex or ill-defined goals. Further, the problem definition may change as exploration for information occurs. In other words, the possible number of options is unknown or sufficiently large to prohibit exploring them all fully. Simon identifies "most corporate strategy problems and governmental policy problems" as being non-structured in nature (Brenner et al., 1996, p. 24). When the environment becomes more turbulent, corporate leaders and planners may perceive a need to change or modify strategies. As it is human nature to seek some degree of certainty, it is natural to accept the first option that satisfices the minimum requirements for a return to stability. Satisficing, by definition, leads to less than optimal decisions. Therefore, a model integrating uncertainty, decision-making, and strategy would be useful to managers for looking beyond the first adequate alternative.

The conventions adopted for Simon's (1963) decision-making dimensions are congruent with the Milliken's (1987) uncertainty dimensions. The greater the strategic importance of an environmental interpretation or decision, the further down the scale it appears. The structured, semi-structured, non-structured pattern repeats three times moving down the uncertainty scale. In Simon's (1963) original decision framework, he did not label the cells formed by the axis intersections. However, he and Baumol (1963) indicated that linear programming fell within the cell defined as normative and structured. The IRM completes the task Simon and Baumol began - placing the appropriate information resources within a useful framework. Ultimately, the goal is to aid managers in aligning information resources and the organization's strategy.

\section{Interpreting the Information Resource Matrix}

The primary purpose of the IRM is to aid managers in making financial allocations and design decisions. In order to make optimal use of the matrix a manager defines their present location on each of the three axes. Next, they determine their preferred location: the strategic posture, the degree of uncertainty they are willing to internalize, and how much information resource cost they are willing to incur. Therefore, the matrix should be read from left to right and top to bottom. The IRM is discussed by highlighting information resource needs for non-structured problems because strategy formulation generally requires this type of analysis (see Table 1). 
Table 1. Information resource matrix - Based on strategy, environmental uncertainty, and decision-making

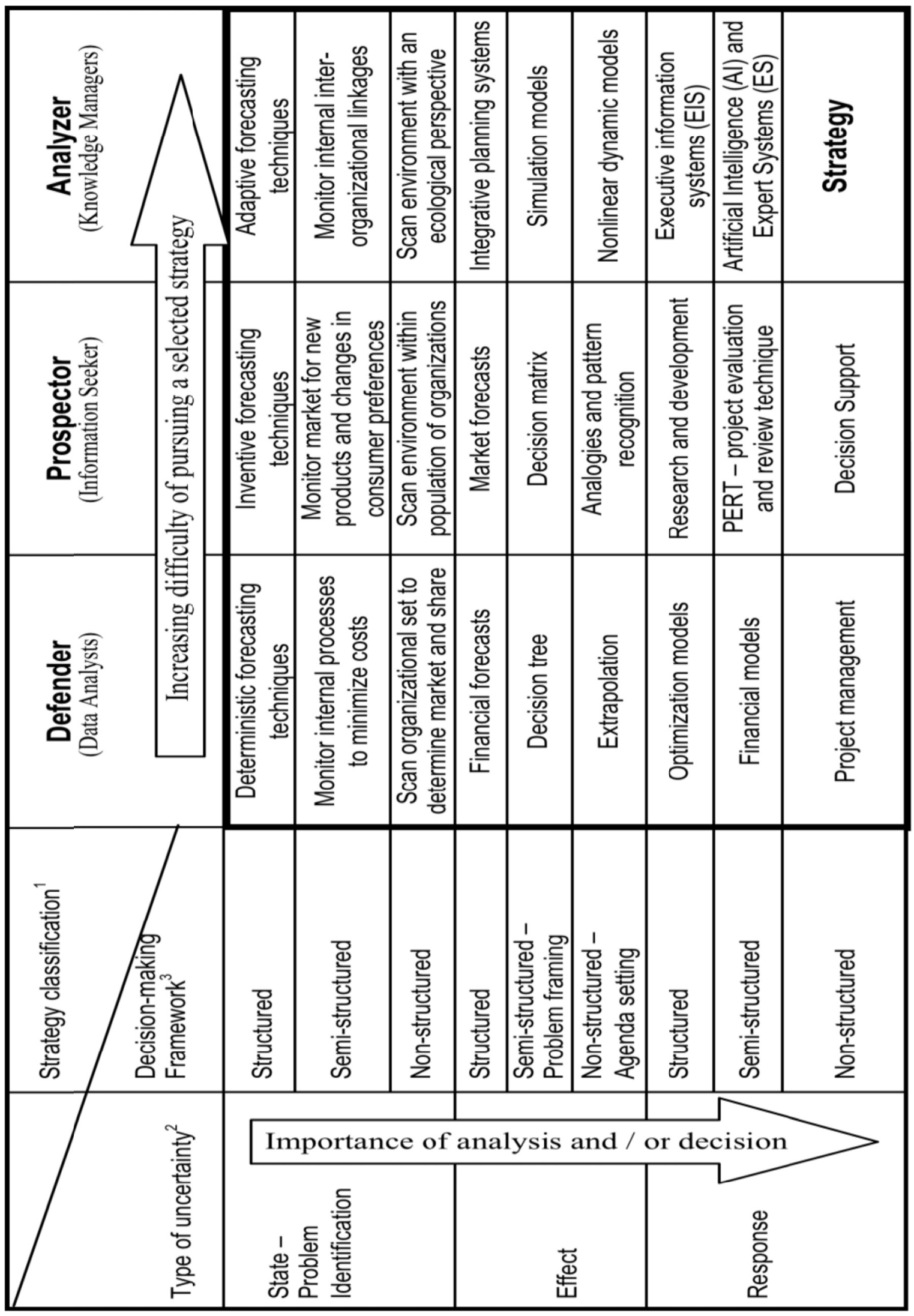




\subsection{Step 1: Strategic Posture Comparison}

The real power of the IRM lies in facilitating moves along the strategic orientation axis. Strategy, by definition, enables bypassing steps in the evolution or iterative processes of an organization's life span. Empirical research has demonstrated that senior executive support and consideration of IT in the strategy development process are key enablers to well-aligned systems (Luftman \& Brier, 1999).

As mentioned previously, companies may move back and forth between defending and prospecting until they fail or until they reach equilibrium as an Analyzer. By moving purposefully to the Analyzer orientation, managers can avoid time and financial losses associated with alternating between Defender and Prospector roles. Further, it encourages conscious design, or re-design, of strategic information systems to achieve synergies through system integration. Finally, using the matrix imposes a structural process that may be useful in future decisions made under conditions of uncertainty.

Defenders are predominantly data analysts. Defender strategies are most effective in relatively stable markets, as the goal is to maintain the current paradigm. Information systems must permit managers to compare current performance against previous experience and against competitors' results. At the state level of uncertainty, Defenders scan their competitive field to monitor their market share. The scanning focus is on identifying threats to their current position. Using information gleaned from market data analysis, Defender organizations attempt to measure their competitors' effect on their own performance. The simplest analytical methods forecast the immediate future by extrapolating past trends. Increasing operational efficiency is a major objective for most Defender organizations. Internal information systems capture data used to evaluate the effectiveness of operational control mechanisms and performance improvement activities (for a Glossary of Terms used in the IRM see Appendix A).

The information system requirements for Defender strategies are primarily data or transaction processing functions. These types of applications were among the first developed and many Defender organizations continue to operate legacy systems in keeping with the cost leadership strategies they favor. When forced into Prospector roles, Defenders may find their information systems are inadequate to compete in new markets or to support product development.

Prospectors are information seekers. Their environmental scanning behavior is directed at identifying opportunities for business development. They require a significant amount of organizational slack to withstand research and development failures and to capitalize on successes.

In addition to having current knowledge of their competitors' activities, Prospectors need to anticipate and perhaps influence future action in the market. They need large amounts of market information, which may require extensive telecommunication resources and significant investment in proprietary information. In addition to capturing or accessing large volumes of information, Prospectors must be able to manipulate it creatively to envision future that is not an extension of the past. Information system applications must be integrated to produce large databases that can be mined for information to initiate product development.

Enacting these futures requires shared vision among managers, perhaps acquired through the use of computer-generated scenarios and simulations. Managers must have the ability and the resources to repeatedly reengineer business processes and to train personnel to accommodate new products and markets. Decision support systems are paramount to the Prospector organization's information system needs.

Prospectors require state-of-the-art information resources, not only to seek and evaluate new business opportunities, but also to be competitive market entrants. In the growing digital marketplace, IT and associated resources are essential business assets, albeit costly ones. Maintaining state-of-the-art IT is difficult. New systems emerge continuously and they may not always interface efficiently with exiting systems.

Analyzers are knowledge managers, seeking to maximize the value of business units over their useful life. When scanning the environment they look at both their own competitors for threats to the existing business, and at other markets and industries for growth opportunities. Information captured in one category is used to aid in making decisions related to the other category. For example, a Prospector might discard a marginal business while an Analyzer retains it to support future ventures. Analyzers acknowledge the complexity of the environment and use nonlinear models to estimate future effects on their organization.

Analyzers use both data processing and information-generating applications to maintain current business lines and to pursue new lines simultaneously. They likely will have hybrid information systems with both legacy and state-of-the-art components. Analyzers with strong Prospector tendencies will have created interfaces to integrate discrete systems, thus producing a virtual database for mining. 


\subsection{Step 2: Environmental Analysis}

The second step, after determining the preferred strategic orientation, is to evaluate threats, opportunities, and stakeholder expectations to determine the state (using the left-most axis) of the business environment (Steiner, 1997). Next, the strategic planner should interpret the effect of the external environment on the company (Daft, Soremunem, $\&$ Parks, 1988). Finally, the manager should formulate responses and specific strategies.

The decision-making framework repeats within each level of uncertainty. While problems initially are viewed as being non-structured in nature, Daft, et al. (1988) found that managers rely on informal information sources more as uncertainty rises or as the problem's structure becomes less clear. The use of informal information sources coupled with the difference between managers' perceptions and objective reality (Bourgeois, 1980) serves to degrade the actual fit between an organization's strategy and the environment. Therefore, the normative behavior is to begin with the known or structured elements of the problem. Reducing initial uncertainty through using objective measures should provide better framing of issues and less reliance on informal, and potentially inaccurate, information resources. This process of moving from a set of 'givens' to the more abstract should be repeated at each level. The next sections briefly describe the contents of the cells taken in $3 \times 3$ groups moving down the matrix.

\subsubsection{State Uncertainty}

Initially, managers work at the State Uncertainty level, where they forecast future trends based on their own structured information systems. The ability to detect changes in the general environment can be enhanced by careful monitoring of the task environment (Dill, 1958). When environmental changes are detected through the task environment, future decisions often are framed or semi-structured upon recognition. A manager must engage in scanning activities to detect changes in the general environment before altering the task environment. Detecting changes prior to them directly affecting an organization allows managers to view the environment in a non-structured context with an array of opportunities. Modifications can be made in the task environment to support strategic intent.

\subsubsection{Effect Uncertainty}

Information resources to reduce effect uncertainty have improved dramatically as computing power has expanded by increasing processing capability and decreasing processing time. For structured problems, the potential effects of environmental changes can be modeled using a variety of forecasting techniques. The most sophisticated integrative planning systems enable matching internal improvements with changing market conditions to provide a future view of a company within the environment. When potential effects of environmental change are less certain, but have a discreet number of possibilities (semi-structure), contingency effects can be considered. If the environmental change presents a non-structured scenario where the range of possibilities cannot be broken down, applications to develop simulation models that consider a range of effects can be utilized.

\subsubsection{Response Uncertainty}

The response level is where managers make tactical and strategic decisions. As asserted earlier, the Defender and Prospector strategies become short-term tactics for Analyzers. Therefore, structured elements, such as optimization models and research and development information, are fed into an Executive Information System (EIS) to facilitate decision-making. Semi-structured decisions can be augmented using Expert Systems (ES) and Artificial Intelligence (AI) to draw information from a variety of databases and simulate human decisions. Tools for use with non-structured problems - those for project management and decision support - are utilized for refining the strategies of Analyzers. Ultimately, managers must decide where their company is going and how to get there - these are the strategic decisions.

\section{Conclusions}

During periods of greater uncertainty, companies need a flexible approach to strategy formulation that is not merely reactive or imitative. The explosion of information availability has been counter-productive in many instances, overwhelming managers and leading to 'paralysis by analysis' on some occasions. This paper provides an analytical framework that relates the types of information needed to specific strategic orientations. Vast amounts of information must be converted into a decision-making resource if strategies are to extend beyond satisficing solutions. A framework for systematically analyzing how to select information resource structures among various options has been described.

The structure and utility of an organization's information resources has become a critical element of strategy research. This paper provides an initial set of criteria for evaluating a company's information systems with respect to its 
strategic orientation, based on Miles and Snow's typology (1978). This structure is useful, as there is empirical support that managers are able to identify their own strategies accurately (Shortell \& Zajac, 1990). Developing an information system that meets an organization's needs should be easier if the manager a priori specifies the firm's strategic orientation.

\section{Limitations and Future Research}

The paper presented is normative and has not been empirically tested. While the Miles and Snow framework has proven to be reliable and valid under other circumstances, more work is needed to assess if it is generalizable to the questions at-hand. In addition, the rapidly changing information technology sector may make some of the applications described obsolete over time. Future research should seek to both qualitatively and empirically test the model proposed. A study using domain area experts would be a useful starting point.

\section{References}

Baumol, William. (1963, October 3). Linear and Integer Programming. Paper presented at the Symposium on Decision Theory, Ohio University Athens.

Bourgeois, L. J., III. (1980). Strategy and environment: A conceptual integration. Academy of Management Review, 5(1), 25-39. http://dx.doi.org/10.2307/257802

Brenner, Lyle A., Koehler, Derek J., Liberman, Varda, \& Tversky, Amos. (1996). Overconfidence in probability and frequency judgments: A critical examination. Organizational Behavior and Human Decision Processes, 65(3), 212-219. http://dx.doi.org/10.1006/obhd.1996.0021

Cho, Y.S. (2013). The effect of business diversification on a firm's performance, depending on Its dynamic capabilities and market dynamism. Journal of Management and Strategy, 4(3), 1-8. http://dx.doi.org/10.5430/jms.v4n3p1

Christensen, Clayton M. (2001). The past and future of competitive advantage. Sloan Management Review, 42(2), 105-109. http://dx.doi.org/10.1126/science.1123633

Clemons, Erik K. (1995). Using scenario analysis to manage the strategic risk of reengineering. Sloan Management Review, 36(Summer), 61-71.

Daft, Richard L., Soremunem, J., \& Parks, D. (1988). Chief executive scanning, environmental characteristics, and company performance: An empirical study. Strategic Management Journal, 9, 123-139.

Daft, Richard L., \& Weick, Karl E. (1984). Toward a model of organizations as interpretation systems. Academy of Management Review, 9(2), 284-295.

Demirci, A. E. (2013). Strategic representation of an abstract reality: Spiraling relations between organizational culture and innovativeness. Journal of Management and Strategy, 4(3), 39-56. http://dx.doi.org/10.5430/jms.v4n3p39

Dill, William R. (1958). Environment as an influence on managerial autonomy. Administrative Science Quarterly, 2(2), 409-443.

Earl, Michael, \& Feeney, David. (2000). How to be a CEO for the information age. Sloan Management Review, 41(2), 11-23.

Gilchrist, Mark, Mooers, Deana Lehmann, Skrubbeltrang, Glenn, \& Vachon, Francine. (2012). Knowledge Discovery in Databases for Competitive Advantage. Journal of Management and Strategy, 3(2), 2-16. http://dx.doi.org/10.5430/jms.v3n2p2

Gonzalez, R., Llopis, J., \& Gasco, J. (2013). Innovation in public services: The case of Spanish local government. Journal of Business Research, 66(10), 2024-2033. http://dx.doi.org/10.1016/j.jbusres.2013.02.028

Highhouse, Scott, \& Johnson, Michael A. (1996). Gain / loss asymmetry and riskless choice: Loss aversion in choices among job finalist. Organizational Behavior and Human Decision Processes, 68(3), 225-233.

Hopper, M. D. (1990). Rattling SABRE -- New ways to compete on information. Harvard Business Review, 90(3), 118-125.

Idris, Wael Mohamad Subhi, \& AL-Rubaie, Methaq Taher Kadhim. Examining the impact of strategic learning on strategic agility. Journal of Management and Strategy, 4(2), 70-78. http://dx.doi.org/10.5430/jms.v3n2p2

Ketchen, D. J., Jr., Thomas, J. B., \& Snow, C. C. (1993). Organizational configurations and performance: A comparison of theoretical approaches. Academy of Management Journal, 36, 1278-1313. 
Khandawalla, P. N. (1972). Environment and its impact on the organization. International Studies of Management and Organization, 2, 297-313.

Korn, Allan. (2004). Professionalism Reconsidered: Physician Payment From A Health Plan Perspective. Health Affairs, 23(6), 48. http://dx.doi.org/10.1377/hlthaff.23.6.48

Koseoglu, M. A., Topaloglu, C., Parnell, J. A., \& Lester, D. L. (2013). Linkages among business strategy, uncertainty and performance in the hospitality industry: Evidence from an emerging economy. International Journal of Hospitality Management, 34, 81-91. http://dx.doi.org/10.1016/j.ijhm.2013.03.001

Lawrence, P. R., \& Lorsch, J. (1967). Organization and Environment. Boston, MA: Harvard University.

Luftman, Jerry, \& Brier, Tom. (1999). Achieving and sustaining business -- IT alignment. California Management Review, 42(1), 109-122.

McKone-Sweet, Kathleen E, Hamilton, Paul, \& Willis, Susan B. (2005). The ailing healthcare supply chain: A prescription for change. Journal of Supply Chain Management, 41(1), 4. http://dx.doi.org/10.1111/j.1745-493X.2005.tb00180.x

Miles, Raymond E., Snow, Charles C., Meyer, Alan D., \& Coleman, Henry J. (1978). Organizational strategy, structure, and process. Academy of Management Review, 3, 546-562.

Milliken, F. J. (1987). Three types of perceived uncertainty about the environment: State, effect, and response uncertainty. Academy of Management Review, 12(1), 133-143.

Navarro, Peter. (2004). Principles of the master cyclist. MIT Sloan Management Review, 45(2), 20.

O'Neill, H. M., Pouder, R. W., \& Buchholtz, A. K. (1998). Patterns in the diffusion of strategies across organizations: Insights from the innovation diffusion literature. Academy of Management Review, 23(1), 98-114.

Parnell, J. A. (2013). Uncertainty, generic strategy, strategic clarity, and performance of retail SMEs in Peru, Argentina, and the United States. Journal of Small Business Management, 51(2), 215-234. http://dx.doi.org/10.1111/jsbm.12010

Pfeffer, Jeffrey, \& Sutton, Robert I. (1999). Knowing "What" to do is not enough: Turning knowledge into action. California Management Review, 42(1), 83-108.

Porter, Michael E. (1980). Competitive Strategy: Techniques for Analyzing Industries and Competitors. New York: The Free Press.

Reich, Blaize H., \& Benbasat, Izak. (1996). Measuring the linkage between business and information technology objectives. MIS Quarterly, 20(1), 55-81.

Reich, Blaize H., \& Benbasat, Izak. (2000). Factors that influence the social dimension of alignment between business and information technology objectives. MIS Quarterly, 24(1), 81-113. http://dx.doi.org/10.2307/3250980

Sambamurthy, V., \& Zmud, Robert W. (1999). Arrangements for information technology governance: A theory of multiple contingencies. MIS Quarterly, 23(2), 261-290.

Shortell, Stephen M., \& Zajac, Edward J. (1990). Perceptual and archival measures of Miles and Snow's strategic types: A comprehensive assessment of reliability and validity. Academy of Management Journal, 33, 817-832.

Simon, Herbert A. (1960). The New Science of Management Decision. New York: Harper \& Brothers Publishers.

Simon, Herbert A. (1963, October 3). A framework for decision making. Paper presented at the Symposium on Decision Theory, Ohio University Athens.

Simon, Herbert A., Dantzig, George B., Hogarth, Robin, Plott, Charles R., Raiffa, Howard, Schelling, Thomas C., .. . Winter, Sidney. (1987). Decision making and problem solving. Interfaces, 17(5), 11-31.

Steiner, George A. (1997). Strategic Planning: What Every Manager Must Know. New York: Free Press.

Weihrich, Heinz. (1982). The TOWS Matrix: A Tool for Situational Analysis. Long Range Planning, 15(2), 60.

Zahara, Shaker A., \& Covin, Jeffrey G. (1993). Business Strategy, Technology Policy, and Firm Performance. Strategic Management Journal, 14, 451-478. 
Appendix A. Glossary of terms used in the Information Resource Matrix

\section{Defender Information Needs}

Deterministic forecasting techniques - calculations and comparisons of stored information used to estimate outcomes expected from following a given course of action, or to determine required courses of action to achieve a desired outcome.

Monitoring internal processes -internal benchmarking using transaction processing systems to generate reports about the current status of operations, perhaps in comparison to historical data; typical reports include inventory status, production and efficiency measures, and cash flow.

Environmental scanning (organizational set) - external benchmarking against competitors in the immediate market; publicly available data are used to determine market share and to compare production efficiency measures using industry standards.

Financial forecasts - use of current status accounting information to forecast revenues, maximize investments, and predict profit or loss.

Decision tree - visual diagrams to illustrates decision alternatives; may include probabilities and conditional risks and rewards; most useful for sequential decisions.

Extrapolation -historical data used to "predict" the future; extension of past trends into future time periods; based on the assumption that current trends will continue relatively unchanged.

Optimization models - prescriptive models such as linear programming used to find the "best" solution to a problem; based on mathematical equations and inequalities that represent objectives and constraints.

Financial models - mathematical models that examine interrelationships among financial variables; used to manipulate financial data for budgeting and budget analysis, and to perform trend and ratio calculations for investment and debt decisions.

Project management - software that integrates various aspects of managing large projects, such as budgeting and costing, scheduling, staffing, and resource management; may include optimization functions such as PERT to search for critical paths or processes that could delay project completion.

\section{Prospector Information Needs}

Inventive forecasting techniques - combining multiple data elements to draw intuitive conclusions from the composite information; for example, using current demographic data in conjunction with historical sales data for a similar product to anticipate market acceptance of a new product.

Monitoring market changes - event-triggered analyses; drops or rises in sales, demographic or geographical trends, or other market phenomena are analyzed to identify causal factors and project emerging trends.

Environmental scanning (population of organizations) -industry-wide analysis anticipating a move into another strategic group, or evaluating another industry for possible entry. 
Market forecasts - analysis of demographic, economic, and social trends to anticipate market preferences and buying behaviors from early signals.

Decision matrix - use of a row by column matrix to compute the expected value of decision alternatives; establishes an "optimal" decision.

Analogies and pattern recognition - application of previous organizational learning to new ventures; data mining to identify potential for product or market development.

Research and development - product and/or market design, development, and evaluation capabilities.

Project evaluation - assessing the efficiency, effectiveness, and impact of implemented projects using expert opinion, cost-benefit analyses, customer surveys, longitudinal trend data, and other outcome measures.

Decision support - use of software designed to assist the manager in analyzing information relevant to a specific decision. The decision maker interacts with the system, modifying variables to construct scenarios.

\section{Analyzer Information needs}

Adaptive forecasting techniques - identifying strategic industry factors (market level) that serve as the prime determinants of success from analysis of data about competing firms, core customers, regulators, disruptive innovators external to the industry, and other stakeholders.

Monitoring inter-organizational linkages - capture and analysis of data resulting from partnerships, joint ventures, and other strategic relationships; may require shared information systems, intranet, or information transfer.

Environmental scanning (ecological perspective) - futuristic portfolio planning; use of scenario development and analysis to anticipate businesses that will be a successful fit in the future environment.

Integrative planning models -information sharing across inter-organizational linkages using intranet/internet technology or integrated information systems.

Simulation models - descriptive models that mimic real world systems; system parameters are coded and used to replicate system inputs, processes, and outputs; time is "compressed" and the effect of changes in inputs and processes on system outputs is examined.

Nonlinear dynamic models -randomly generated variables with small influences are used to construct unique models; mimics the conditions associated with strategic thinking, where decisions are holistic, rather than context free.

Executive information systems - integration of data from internal information systems with information from selected external sources; capable of analyzing the composite data and evaluating scenarios.

Artificial intelligence/Expert systems - applications programmed to "think and reason" based on analysis of relevant relationships among data variables and defined decision-making processes. The knowledge base stored in the system is derived from human expert knowledge. 